\title{
先天性内反足の発生とその季節的変動について
}

\author{
九州大学整形外科 \\ 大 宮 克 弘・野 口 康 男 \\ 井原和彦・杉岡洋一 \\ 福岡市立こども病院整形外科 \\ 藤 井 敏 男・柳 田 晴 久
}

\section{Seasonal Variation in the Incidence of Congenital Talipes Equinovarus}

by

\author{
Katsuhiro Omiya, Yasuo Noguchi, Kazuhiko Ihara \\ and Yoichi Sugioka \\ Department of Orthopedic Surgery, \\ Faculty of Medicine Kyushu University, Fukuoka, Japan

\section{Toshio Fujii and Haruhisa Yanagida \\ Fukuoka Chidrens Hospital}

A seasonal variation in the incidence of congenital talipes equinovarus in England was reported previously. A review of 218 neonates who presented to Kyushu University Hospital and Fukuoka Children's Hospital with congenital talipes equinovarus over a ten-years period revealed an increase in the condition amongst babies born during winter.

This finding was particularly apparent among cases with more severe club foot. Possible reasons for this seasonal variation are discussed.

\section{はじめに}

イギリス，ケンブリッジ地方における先天性内反足 の季節による発症の相違が，1991 年，Pryor らによっ て調査され，冬期に出生した児に，その発症が有意に 多いことが報告された，今回，我々は福岡における先 天性内反足の月別出生数を調査し，その変動について 検討を行ったので，文献的考察を加え報告する.

\section{症例および方法}

症例は, 1981 年以降当科ならびに福岡こども病院に 先天性内反足のため受診した 218 例である。内訳は， 手術例 80 例, corrective cast による保存的治療例 138 例であった，方法は，まず，全症例について，出生月 別の症例数を算出し，さらに，これを手術例および保
存的治療例の 2 群に分け, 同様に検討し統計学的処理 を行った，検討の前提として，出生数が月別で変動が ないかを知るために, 福岡県における過去 10 年間の出 生数の統計を調査したところ各月別において，その出 生数には有意な差は認められなかった（図 1).

結果

全症例における出生月別の症例数を調査の結果, 10 月から 1 月にかけてと，6月に出生した児に内反足の 発生が多い傾向がみられるが，各月別に統計学的に検 討しても有意な差は得られなかった（図 2).

次に，治療法別（保存的治療例と手術治療例）にそ の出生月別の症例数を調査したところ, 保存的治療例 では，月別出生数は全症例と類似した傾向が認められ 有意な差は得られなかった（図 3 ). 


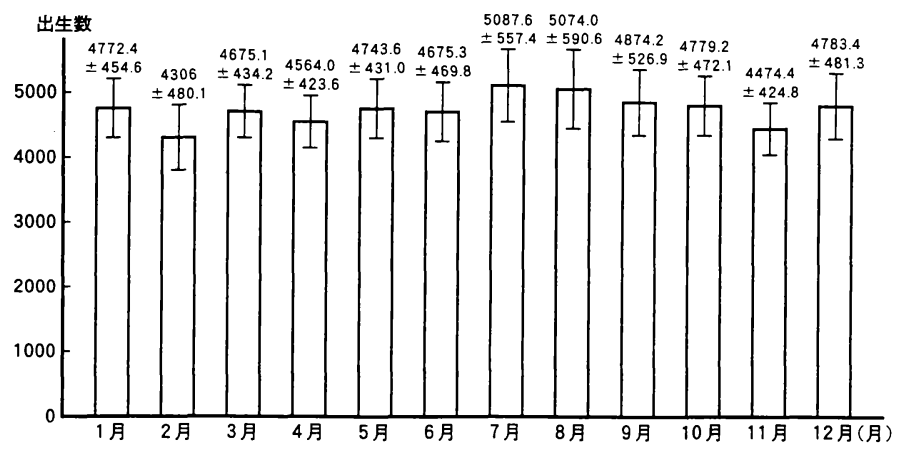

図 1 福岡県月別出生数（過去 10 年間）

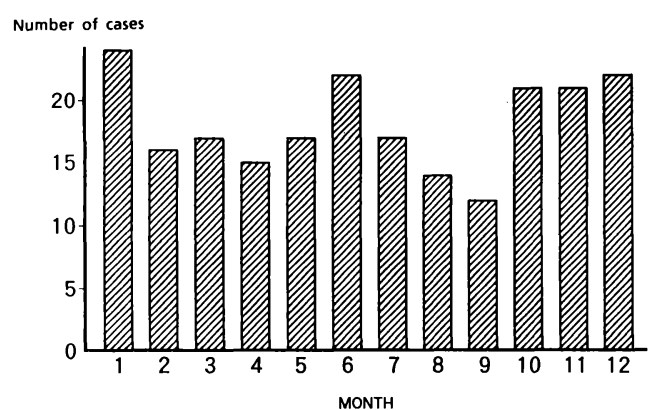

図 2 全症例

一方, 比較的重症例と考えられる手術治療例では, 12 月から 3 月にかけて, 内反足の発生が多い傾向が見 られ，保存的治療例に見られた 6 月頃のピークはなく， 統計学的には有意な差が認められた（図 4 ）.

\section{考察}

1991 年 Pryor らは, イギリスケンブリッジ地方にお ける過去 10 年間の内反足の発生を月別に認查し, 内反 足の発生は, 冬期に多く, 統計学的にも有意な差を認 め, 何らかの環境的な因子が関与していることを示唆 するとした (図 5 ).

当科の症例と Pryor らの症例について, その発生数 を全症例について比較してみた.当科では 6 月と 10 月 から 1 月にかけて, 2つのピークを認め, 彼らの症例 では，1月にピークが認められ，パターンが異なって いた（図 6 ).

先天性内反足の病因には様々な説があるが，未だは つきりとした病因については，解明されていない．古 くは子宮圧迫説, 神経筋原性疾患, 一次肧芽欠損説な

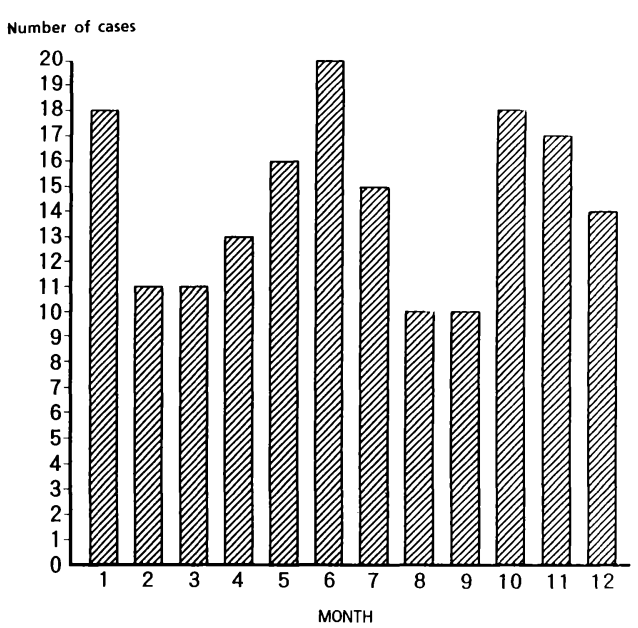

図3 保存的治療例

どが提唱されている.

一方, 季節的変動を説明するのに, ウイルス感染説 や maternal hyperthermia は興味のあるところであ る. Edwards らは, 実際にモルモットによる動物実験 で，妊娠期間中に incubater にて高温中に頻回さらさ れたモルモットでは, その仔に内反足の発生が有意に 多かったことを示している.

今回明らかになった英国と福岡においての出生月別 のパターンの違いは, 世界各地域におけるウイルス感 染の分布や気候, 風土の違いが内反足の発生に影響を 及ほしていることを示唆するものかもしれない. 今後 南半球や熱帯地方などにおけるデータが明らかになれ ば，さらに環境因子の関与についての詳細が明らかと 


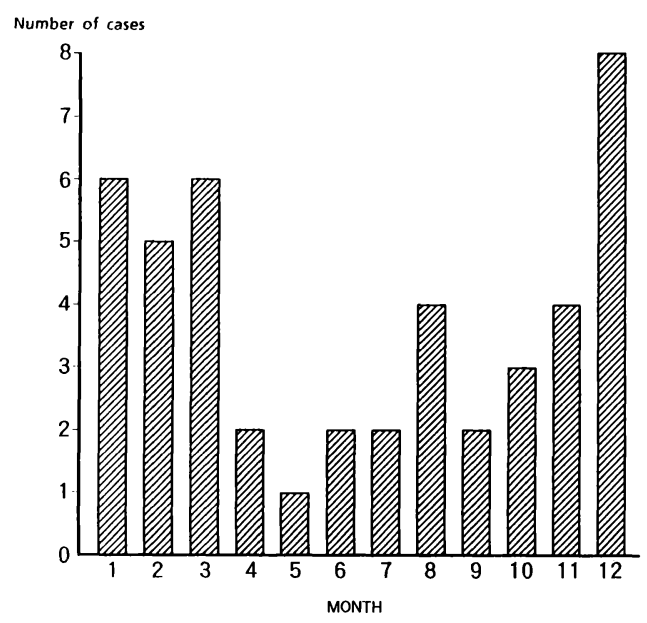

図 4 手術例

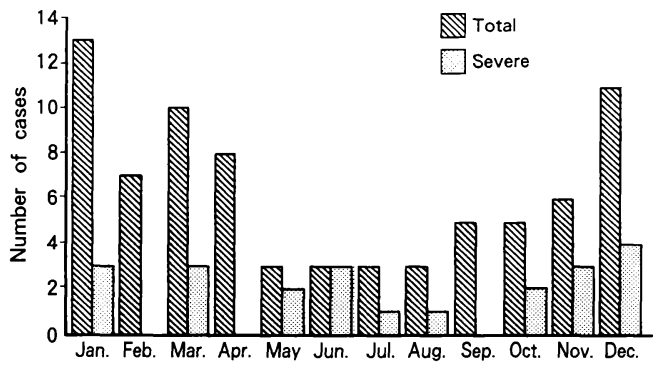

図 5 イギリスケンブリッジ地方における先天性内反足の 発生数

(Britsh JBJS $1991 ; 73-\mathrm{B}$ 632-4)

なることが期待される。

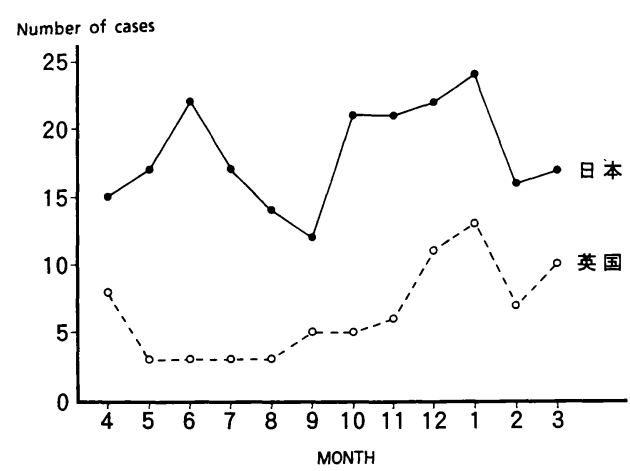

図 6 福岡（九大，こども病院）とケンブリッジ（英国）に おける違い（全症例）

\section{ま と め}

1. 先天性内反足の発生には季節的変動が認められ

る.

2. 手術治療例は冬期に出生する例に多い.

3. 本症には環境因子の関与が示唆される。

\section{参 考 文 献}

1) Edwards, M. J. The experimental production of clubfoot in Guinea-pigs by maternal hyperthermia during gestation. J. Pathol. 103 : 49-53, 1971.

2) Laurence, K. M. The recurrence risk in spina bifida cystica and anencephaly. Develop. Med. Child Neurol. (Suppl) $20: 23-30,1969$.

3) Pryor, G. A. et al. Seasonal variation in the incidence of congenital oalipes equinovarus. J. Bone Joint Surg. [Br] 73-B : 632-4, 1991. 